\title{
DAMAGE EVOLUTION DURING COMPRESSIVE HOLD SUSTAINED PEAK LOW CYCLE FATIGUE OF A Ni-BASED SINGLE-CRYSTAL SUPERALLOY
}

\author{
Swapnil Patil ${ }^{1}$, Shenyan Huang ${ }^{2}$, Mallikarjun Karadge ${ }^{2}$, Doug Konitzer ${ }^{3}$, Akane Suzuki ${ }^{2}$ \\ ${ }^{1}$ General Electric Global Research, Bangalore, Karnataka 560066, India \\ ${ }^{2}$ General Electric Global Research, Niskayuna, NY 12309, USA \\ ${ }^{3}$ General Electric Aviation, Cincinnati, OH 45215, USA
}

Keywords: hold-time fatigue, crack growth, hysteresis loops, creep

\begin{abstract}
The damage evolution in a Ni-base single-crystal superalloy during compressive hold sustained peak low cycle fatigue (SPLCF) was investigated by conducting series of interrupted SPLCF tests using René N5 at 982 and $1093{ }^{\circ} \mathrm{C}$. Evolution of hysteresis loops and microstructure in the bulk away from surface cracks were analyzed to understand bulk damage accumulation. Tensile stress developed during SPLCF was found to be a key factor for crack propagation and life. Bulk deformation away from cracks showed a signature of dominant creep deformation, including $\gamma^{\prime}$ rafting and formation of interfacial dislocation networks. Crack depth measurements along with detailed microstructural investigations of cracks were performed to understand crack growth behavior. Based on the experimental results, a comprehensive SPLCF crack growth model was developed by combining a finite element method (FEM) simulation of oxide induced crack growth and linear elastic fracture mechanics (LEFM) based approach.
\end{abstract}

\section{Introduction}

Sustained-peak low cycle fatigue (SPLCF) resistance is one of the important properties required for Ni-based single-crystal superalloys. SPLCF deformation involves fatigue, creep and oxidation, and it is important to understand how these degradation processes contribute to the SPLCF damage evolution. SPLCF damage can be divided into two parts: bulk damage accumulation and crack nucleation followed by propagation.

Literature involving SPLCF behavior of single crystal superalloys is quite limited [1-7]. Typical bulk microstructure after compressive SPLCF failure in $\mathrm{CMSX}-4^{\circledR}\left(\mathrm{CMSX}-4^{\circledR}\right.$ is a registered trademark of Cannon Muskegon Corporation) and René $\mathrm{N} 5$ were reported as the formation of discontinuous p-type rafts during compressive dwell, caused by dislocation activities in both vertical and horizontal $\gamma$ channels during creep-fatigue interaction $[1,5,7]$. These rafts seem to have less resistance to dislocation motions than the long continuous rafts developed during creep. However, the SPLCF bulk damage mechanisms and damage evolution during cyclic deformation are not well understood from these earlier studies. Many cracks were found to initiate from surface oxide spikes at high temperatures [1-7]. To explain the surface nucleation and propagation of SPLCF crack Evans and colleagues [10-12] proposed a mechanism of oxide assisted crack growth. However, their oxide assisted crack growth mechanism and/or fatigue crack growth mechanism alone cannot explain observed failure life in SPLCF experiments.
In this study, several interrupted SPLCF tests were conducted to understand the SPLCF crack initiation and growth mechanisms along with the bulk damage evolution in a Ni-base single-crystal superalloy René N5. Focus was restricted to compressive SPLCF deformation. Analyses of hysteresis loops and microstructure evolution in the bulk away from surface cracks were performed to identify bulk damage and its correlation with SPLCF life. Based on detailed microstructural investigations of cracks, a comprehensive SPLCF crack growth model was developed in this study. A finite element method (FEM) simulation of oxide induced crack growth and linear elastic fracture mechanics (LEFM) based approach was employed to model SPLCF life.

\section{Experimental Procedures}

SPLCF tests were conducted on a bare Ni-base single-crystal superalloy René N5 with loading direction parallel to [001] crystallographic orientation within 8 degrees of misorientation. Tests were conducted isothermally at $1093{ }^{\circ} \mathrm{C}$ and $982{ }^{\circ} \mathrm{C}$ in air, under strain-controlled condition with $\mathrm{A}=-1$ and total strain ranges $0.4,0.7$ and $0.9 \%$. The specimen was held in compression at a peak compressive strain for 2 minutes, and strain was then returned to zero. Tests were terminated at about 10, 25, 50, 75 and $100 \%$ of the expected SPLCF life. Detailed microstructural characterization using optical microscopy, scanning electron microscopy (SEM) and transmission electron microscopy (TEM) was conducted on longitudinal sections of the specimens. TEM specimens for bulk deformation studies were prepared by conventional slicing and electropolishing technique while specimens from crack tip locations were prepared by focused ion beam milling (FIB). Fractography was also performed on specimens tested to failure.

\section{Hysteresis Loop Analysis}

Typical SPLCF stress-strain hysteresis loops are illustrated in Figure 1(a). Reasonable repeatability in hysteresis loops was confirmed by comparing data of interrupted tests and the test to failure. With increasing cycle, loop shifts to the tensile stress direction mainly due to the stress relaxation during the 2 minute hold, which leads to tensile mean stress. Stress and strain parameters from loop analysis are also defined schematically in Figure 1(a). As an example, evolution of maximum, minimum, mean stresses, total stress range, cyclic stress range, stress relaxation at $982{ }^{\circ} \mathrm{C}$ and $0.7 \%$ total strain range is plotted in Figure 1(b), which can be divided into three stages throughout the life. At early stage of SPLCF within the first 20 50 cycles, stress relaxation during 2 minute hold continuously decreases and cyclic stress range defined as total stress range extracted by stress relaxation increases, which indicate cyclic hardening. Plastic strain range per cycle decreases accordingly. The intermediate 

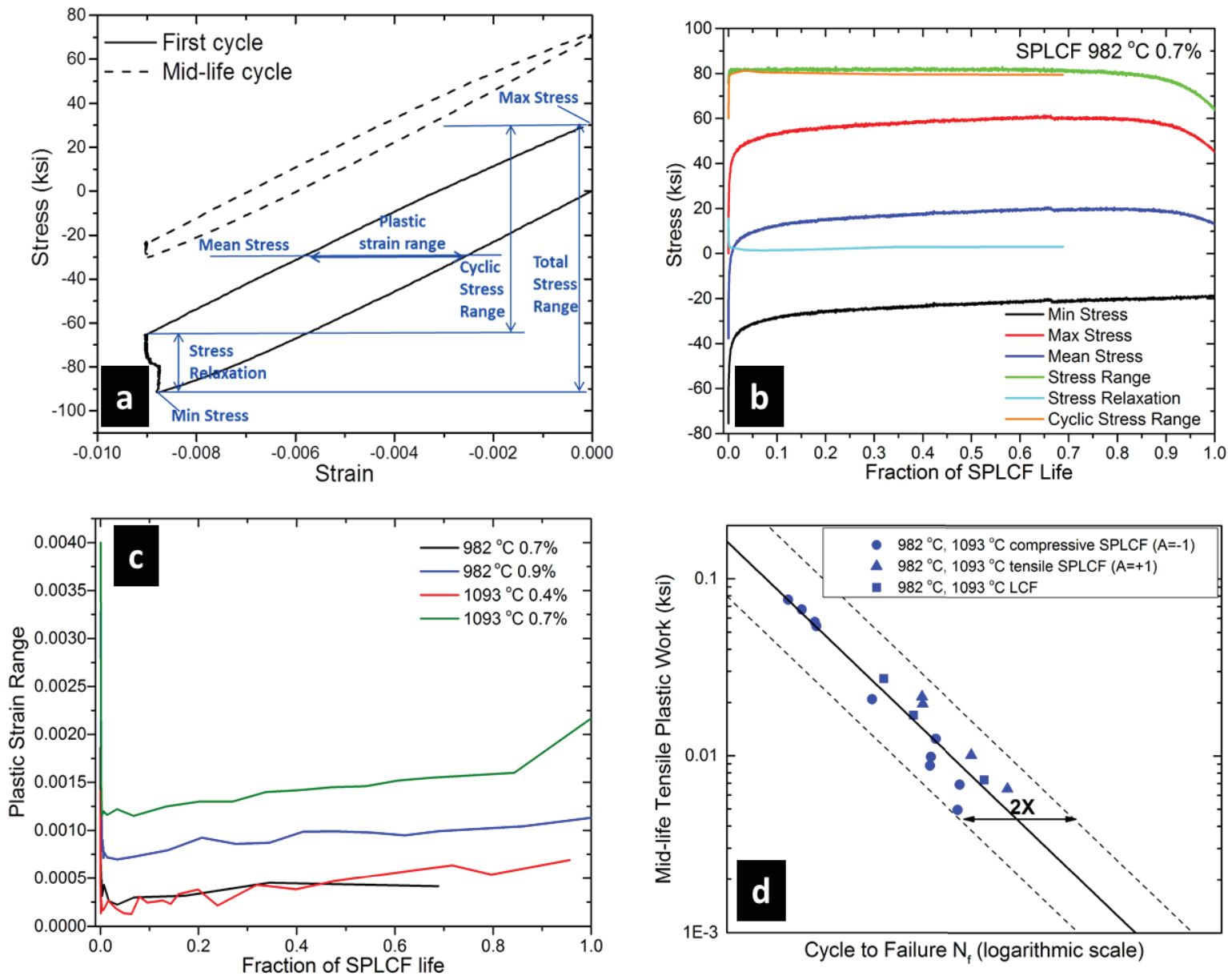

Figure 1. (a) First cycle and mid-life hysteresis loops for $982{ }^{\circ} \mathrm{C}$ and $0.9 \%$ total strain range. Stress, strain terminologies schematically defined on hysteresis loop; (b) evolution of maximum, minimum, mean stress, stress range, stress relaxation, and cyclic stress range at $982{ }^{\circ} \mathrm{C}$ and $0.7 \%$ total strain range; (c) evolution of plastic strain range at different conditions; (d) mid-life tensile plastic work versus cycle to failure for different testing conditions: compressive SPLCF, tensile SPLCF, LCF without hold time at $982{ }^{\circ} \mathrm{C}$ and $1093{ }^{\circ} \mathrm{C}$.

stage of SPLCF took $80 \sim 90 \%$ of life, where stress relaxation and cyclic stress remained stabilized as constants while mean stress and plastic strain range showed gradual increase. The late stage of SPLCF is marked by a rapid stress drop, which is usually associated with long crack propagating to a critical size causing the final overload fracture.

In general, similar trends of stress/strain evolution were observed at other SPLCF conditions. With total strain range increases, all the stress parameters increase along with plastic strain range except minimum stress. Higher temperature results in higher plastic strain range (Figure 1(c)), stress relaxation, and minimum stress, but lower total stress range, cyclic stress range, maximum, mean stresses. Ostergren [8] proposed using the tensile plastic work (area inside hysteresis loop under tensile stress) as low cycle fatigue damage indicator based on the assumption that crack propagation is mainly driven by tensile stress. His damage model considers mean stress and hold-time effects, and seems to well correlate with life for a range of steels and Ni-based polycrystalline superalloys. Figure $1(d)$ plots tensile plastic work at mid-life cycle versus cycle to failure for René N5 under compressive SPLCF $(\mathrm{A}=-1)$, tensile SPLCF with 2 min hold (A $=+1)$, and LCF tests without hold time $(\mathrm{A}=-1)$. Data with different wave forms, test temperatures, and total strain range collapse onto a master curve within $2 \mathrm{X}$ scatter band. This suggests that tensile stress plays a critical role in SPLCF deformation.

\section{Bulk Microstructure Evolution}

Microstructure in the gage section of the interrupted SPLCF specimens was characterized to reveal the signature of bulk damage evolution. At early stage of SPLCF, TEM investigations of a specimen interrupted at the $10^{\text {th }}$ cycle at $982{ }^{\circ} \mathrm{C}$ and $0.7 \%$ total strain range (Figure 2(a) and 2(b)) showed a combination of significant yield and creep deformation, which agreed with cyclic hardening and the large magnitude of stress relaxation found in loop analysis. Early stage yielding also exhibited an inhomogeneous planar faulting and slip band activity. Both yield and creep damage were predominantly realized by octahedral 

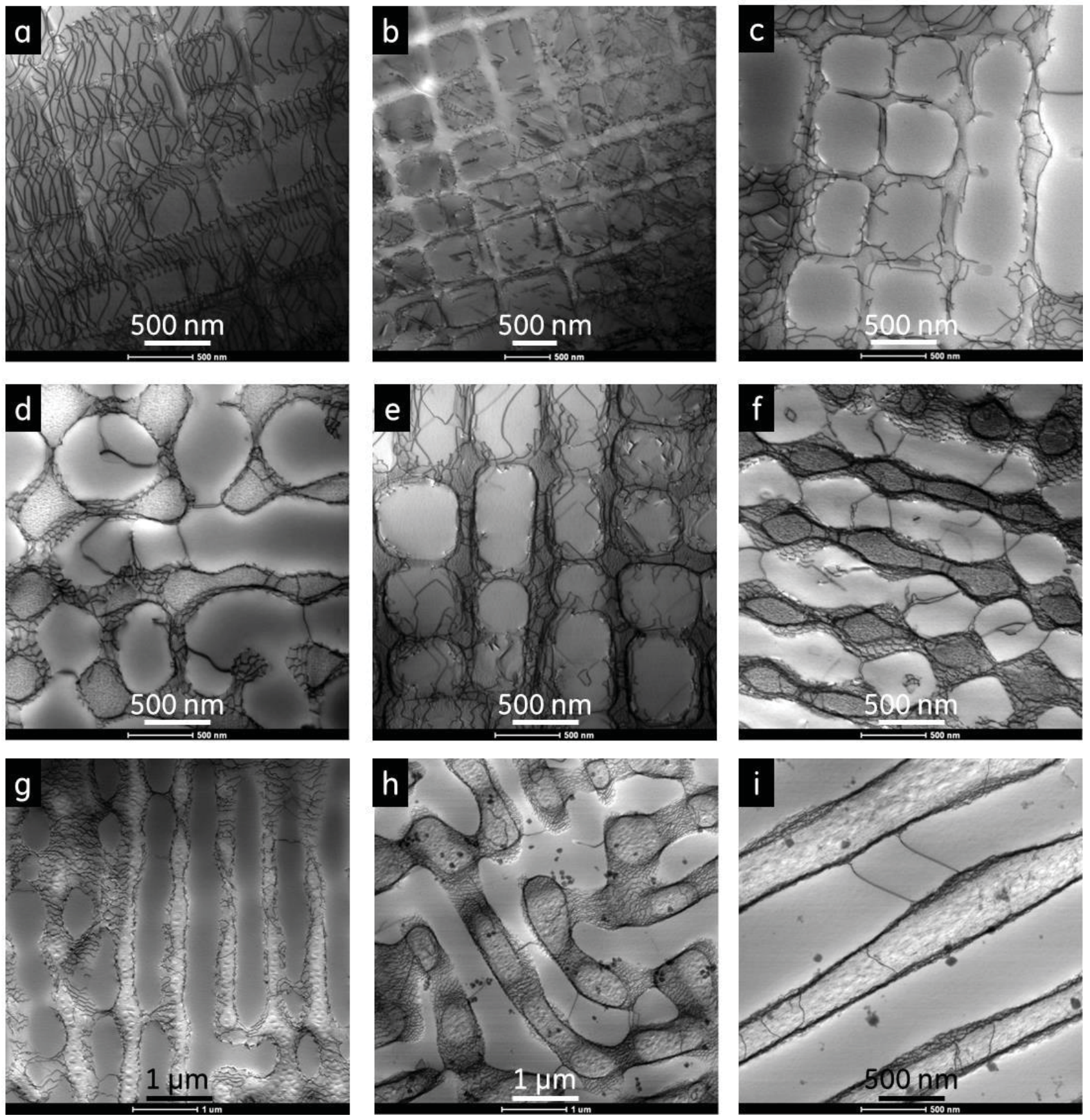

Figure 2. $\gamma^{\prime}$ morphology and defect structures in compressive SPLCF specimens: (a,b) $982{ }^{\circ} \mathrm{C}, 0.7 \%$ total strain range, 10 cycles, (c) $982{ }^{\circ} \mathrm{C}, 0.7 \%$ total strain range, $10 \%$ life, (d) $982{ }^{\circ} \mathrm{C}, 0.7 \%$ total strain range, $62 \%$ life, (e) $982{ }^{\circ} \mathrm{C}, 0.9 \%$ total strain range, $10 \%$ life, (f) $982{ }^{\circ} \mathrm{C}, 0.9 \%$ total strain range, $80 \%$ life, (g) $1093{ }^{\circ} \mathrm{C}, 0.7 \%$ total strain range, $10 \%$ life, (h) $1093{ }^{\circ} \mathrm{C}, 0.7 \%$ total strain range, $76 \%$ life and (i) pairwise shearing of $\gamma^{\prime}$ rafts, at $1093{ }^{\circ} \mathrm{C}, 0.4 \%$ strain range, rupture.

$1 / 2<110>$ dislocation activity: propagation by cross-slip within the $\gamma$ channels and pairwise shearing of $\gamma^{\prime}$.

At intermediate stage of SPLCF, significant dislocation annihilation and formation of interfacial dislocation network were observed (Figure 2(c)), which was representative of creep deformation mode. The signatures of yielding upon loading and unloading per cycle appeared to have been erased during compressive hold regimes, in contrast to Figure 2(a). This may also be related to the fact that plastic strain range and stress relaxation both have lower values from loop analysis compared to early stage. By comparing Figure 2(c), (d), (e), (f), (g) and (h), it can be seen qualitatively that low temperature, higher strain range, and higher number of cycles led to increased dislocation activity and also increased pairwise shearing of $\gamma^{\prime}$. At higher temperatures $\left(1093{ }^{\circ} \mathrm{C}\right)$, a rafted structure evolved very early in life with a high 

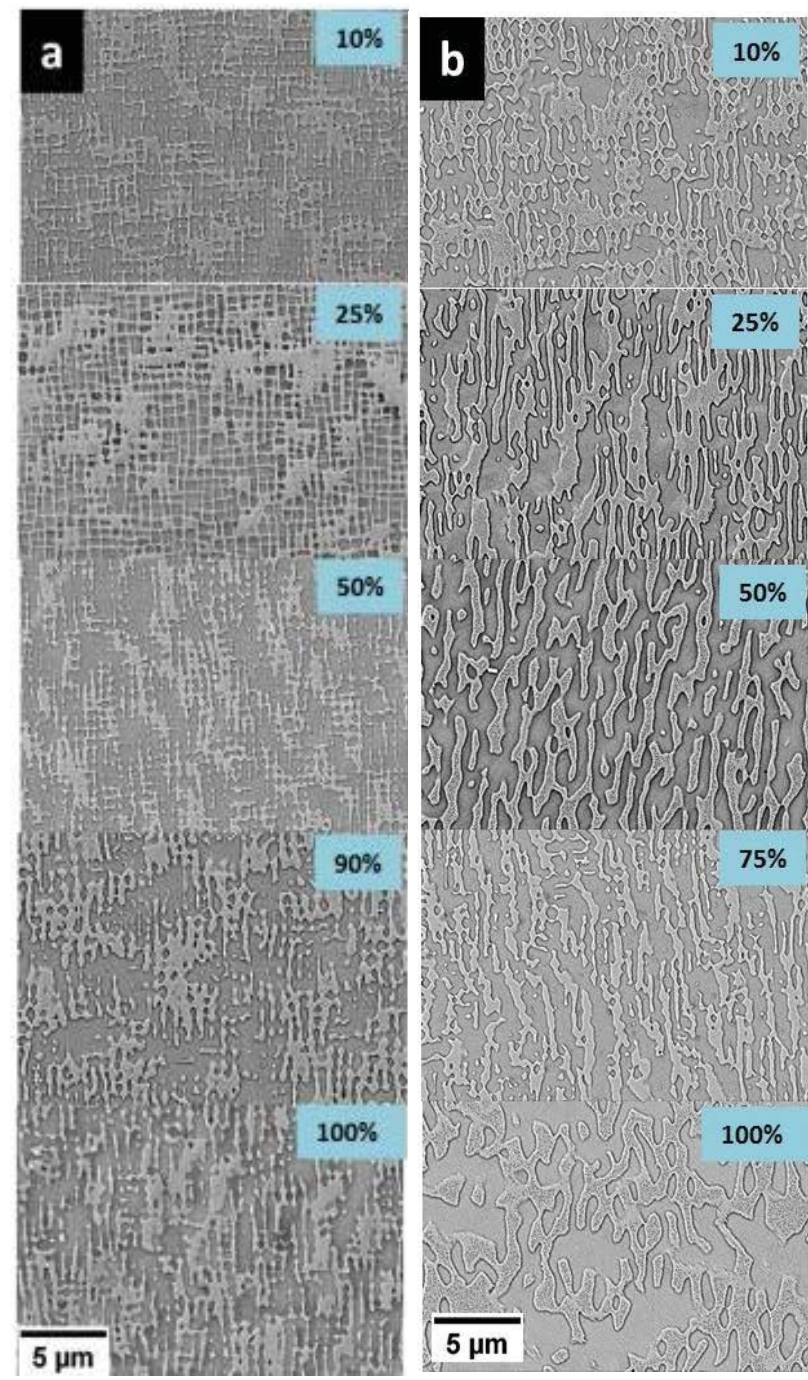

Figure 3. $\gamma^{\prime}$ rafts observed in SPLCF specimens interrupted at different fractions of life: (a) $982{ }^{\circ} \mathrm{C}$ and $0.7 \%$ total strain range, (b) $1093{ }^{\circ} \mathrm{C}$ and $0.7 \%$ total strain range. Vertical direction of the images is parallel to loading direction. The dark contrast phase is $\gamma^{\prime}$ and the bright contrast phase is $\gamma$.

density of interfacial dislocations. Later lives during high temperature SPLCF involved pairwise $\gamma^{\prime}$ raft shearing and formation of a corrugated raft structure. Pairwise shearing is demonstrated in Figure 2(i), where a $\gamma^{\prime}$ raft is sheared by pairs of $1 / 2<110>$ dislocations. This is consistent with loop analysis that plastic strain range increases slightly with cycles while stress relaxation reaches a constant (Figure 1).

Another feature at this stage was the evolution of $\gamma^{\prime}$ rafting as a result of creep deformation during the hold time. Consistent with [7], $\gamma^{\prime}$ rafts parallel to loading direction were seen in compressive SPLCF, indicating the dominant deformation is compressive in nature despite the both compressive and tensile stresses experienced by the specimen. Unlike long and continuous rafts observed in creep deformed materials, the rafts were short and less connected. As pointed out in [7], this may be attributed to

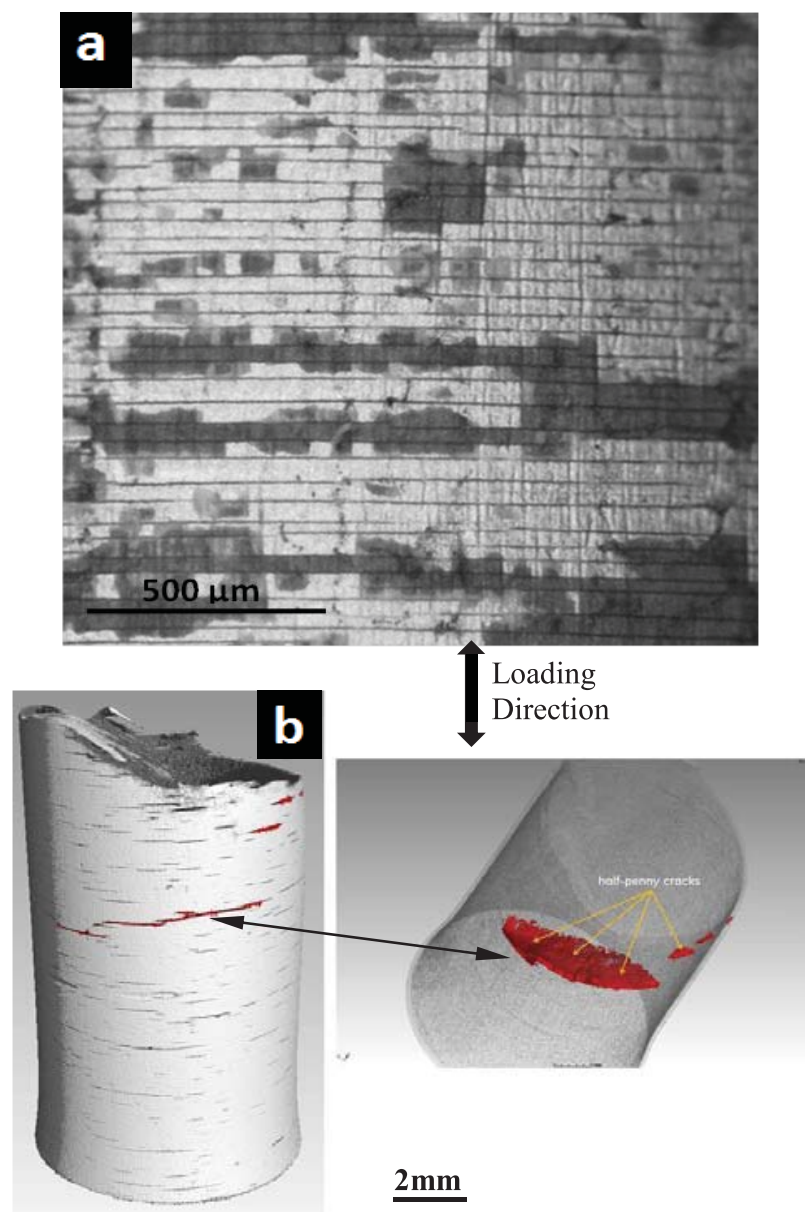

Figure 4. (a) Optical micrograph of external surface showing regular segmentation of the surface TGO layer and (b) X-ray microtomography reconstruction showing a few surface segmentation cracks evolving into thumb-nail shaped cracks $\left(1093{ }^{\circ} \mathrm{C}, 0.4 \%\right.$ total strain range, $\mathrm{A}=-1,2$ min hold, tested to failure.

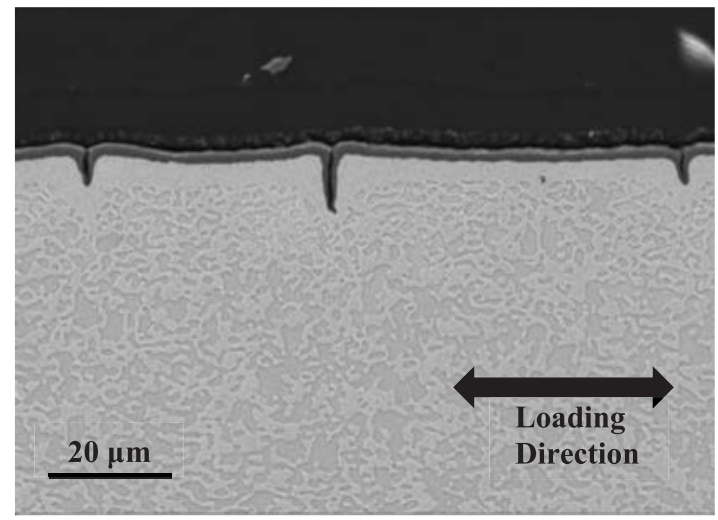

Figure 5. SEM micrographs of a longitudinal section showing segmentation crack and subsequent oxidation induced crack growth at $1093{ }^{\circ} \mathrm{C}$ and $0.4 \%$ total strain range. 

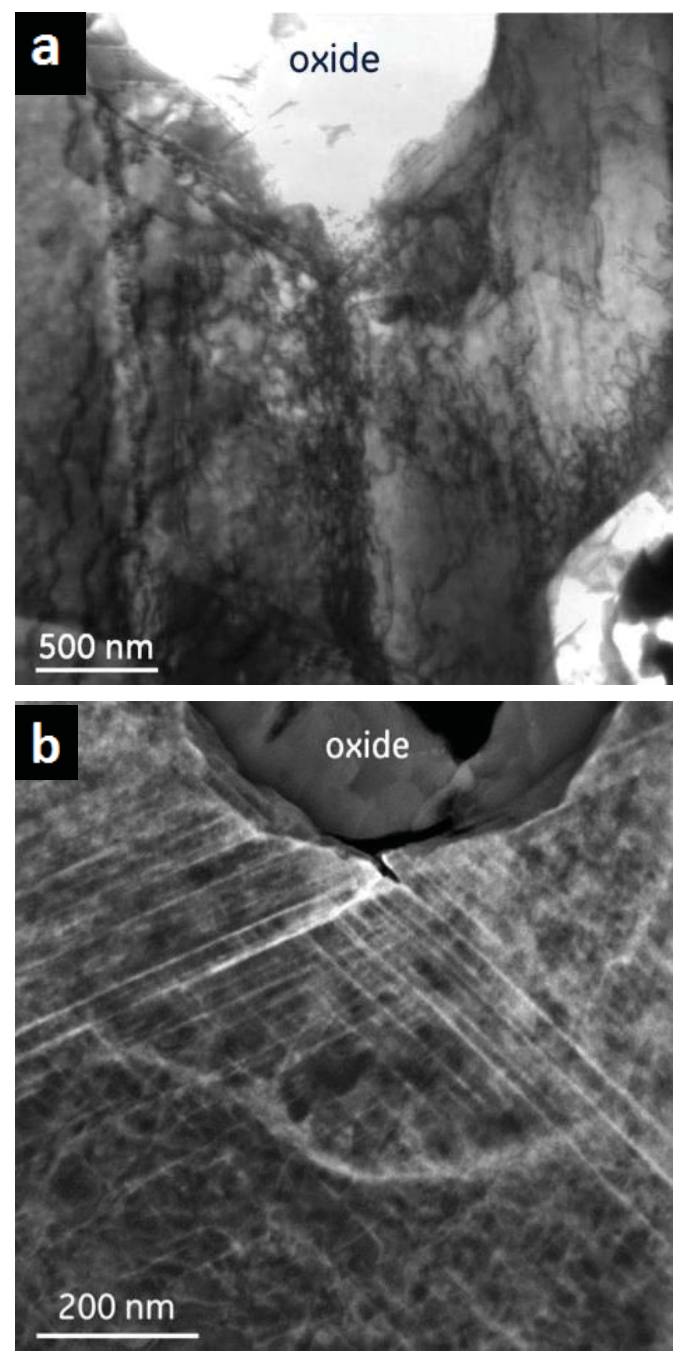

Figure 6. TEM micrographs of (a) a short crack showing converging slip lines ahead of the crack (about $30 \mu \mathrm{m}$ deep, $1093{ }^{\circ} \mathrm{C}, 0.4 \%$ total strain range, $\mathrm{A}=-1,2 \mathrm{~min}$ hold) and (b) a long crack showing diverging slip lines ahead of the crack tip (crack $160 \mu \mathrm{m}$ deep, $1093{ }^{\circ} \mathrm{C}, 0.4 \%$ total strain range, $A=-1,2 \mathrm{~min}$ hold).

combined effect of cyclic and creep deformation. Higher temperature accelerates rafting kinetics. Figure 3 shows that rafting started beyond $25 \%$ of life at $982{ }^{\circ} \mathrm{C}$ and initiated before $10 \%$ of life at $1093{ }^{\circ} \mathrm{C}$. At $982{ }^{\circ} \mathrm{C}$ up to $75 \%$ of life, rafting and dislocation structure evolutions did not seem to cause obvious stress change. At $1093{ }^{\circ} \mathrm{C}$ after $75 \%$ of life, inclined or corrugated rafts not aligned with loading axis were observed together with slight cyclic softening, which could well be attributed to $\{111\}$ slip damage accumulation and strain accommodation. As a result of rafting evolution and coalescence of $\gamma^{\prime}$ particles, topological inversion of $\gamma / \gamma^{\prime}$ was also found, where $\gamma$ was the matrix before testing and $\gamma^{\prime}$ became matrix at certain point during testing. It can be seen from Figure 3 that topological inversion occurs beyond $75 \%$ of life at $982{ }^{\circ} \mathrm{C}$, while it happens beyond $25 \%$ of life at $1093{ }^{\circ} \mathrm{C}$. Topological inversion was
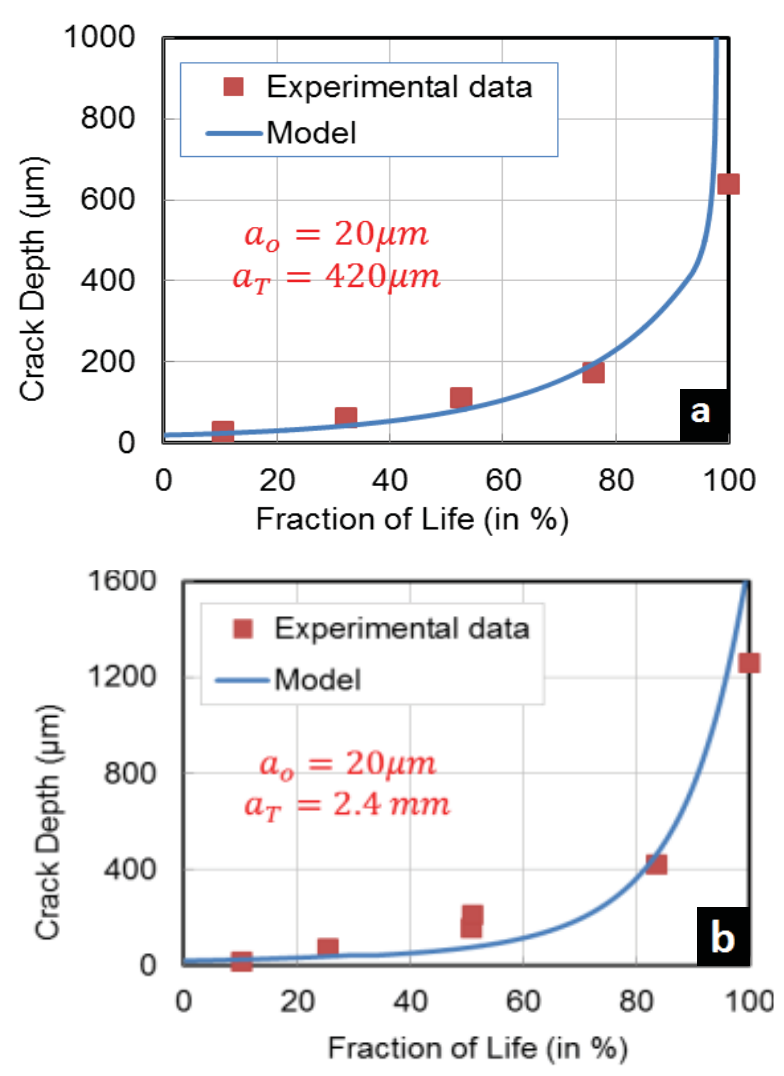

Figure 7. Crack depth at various stages of SPLCF life (a) $1093{ }^{\circ} \mathrm{C}$ and $0.4 \%$ total strain range and (b) $982{ }^{\circ} \mathrm{C}$ and $0.9 \%$ total strain range. $a_{o}$ and $a_{T}$ represent the initial flaw size and crack depth when mechanism transition occurs in LEFM based model calculations.

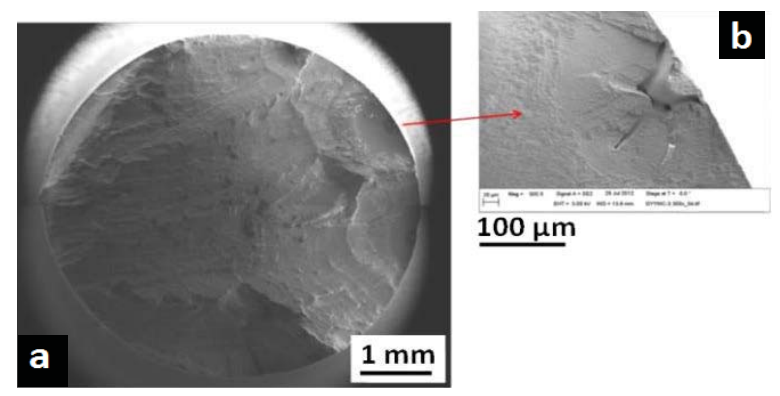

Figure 8. Fractographs of typical SPLCF specimen cycled to failure at $1093{ }^{\circ} \mathrm{C}$ and $0.4 \%$ total strain range. (a) Multiple surface crack initiation sites and (b) Surface crack associated with casting pores close to the surface.

reported in creep deformed SRR99, and seemed to mark the transition from quasi-stationary creep to accelerated creep [9].

At late stage of SPLCF, higher dislocation activities and higher number of pairwise shearing in $\gamma^{\prime}$ were found, which agreed with increase of plastic strain range from hysteresis loops. The increased bulk damage was associated with increasing fatigue crack propagation. Till the end of life, creep voids typically seen in creep rupture were not observed, consistent with fatigue failure mode seen in fractography. 


\section{Complete Fatigue Life}
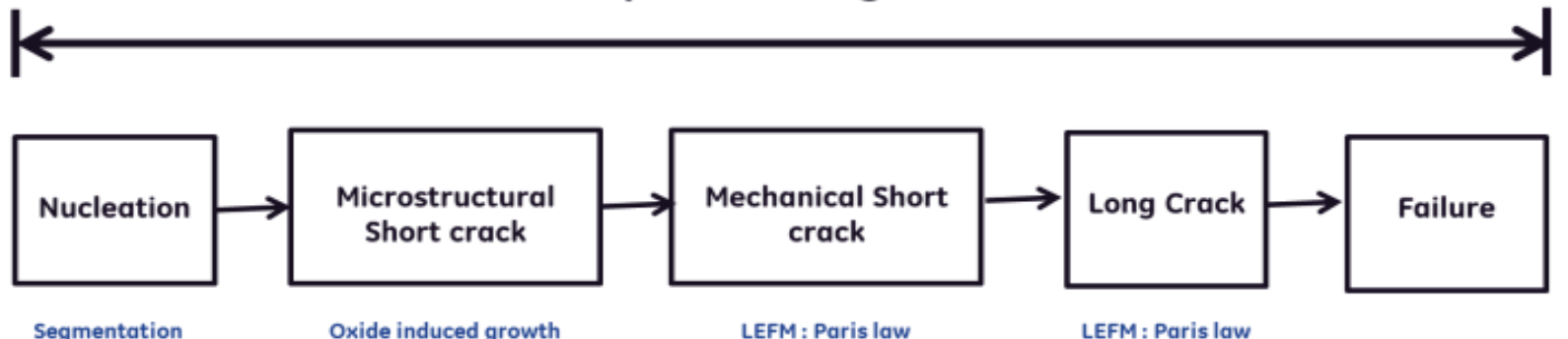

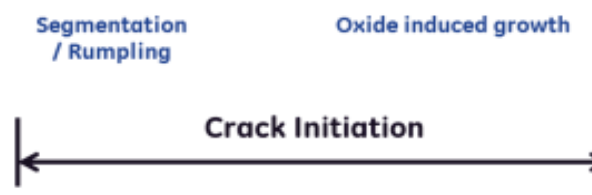

Stage I

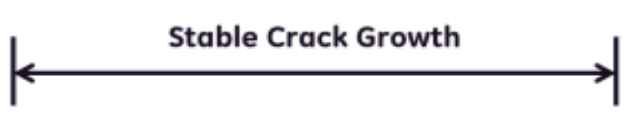

Stage II

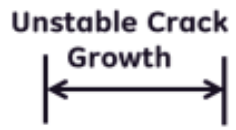

Stage III

Figure 9. Schematics of different stages of SPLCF crack growth.

\section{Crack Nucleation and Growth Behavior}

After SPLCF tests, specimens revealed regularly spaced segmentation cracking of a thermally grown oxide (TGO) layer on the surfaces as shown in Figure 4(a). The spacing between the two neighboring cracks was about 10 to $15 \mu \mathrm{m}$, and the depth was about 1 to $2 \mu \mathrm{m}$ according to TEM observation. The TGO layer mainly consisted of $\mathrm{Al}_{2} \mathrm{O}_{3}$ with a columnar grain structure. The segmentation cracks in the TGO layer occurred during unloading phase of a SPLCF cycle due to the generation of tensile stress. A few of the surface segmentation cracks evolved into thumbnailshaped cracks as shown in the X-ray microtomography reconstructions (Figure 4(b)). Longitudinal cross section in Figure 5 shows that most of the TGO segmentation cracks further penetrated into the substrate giving numerous incipient SPLCF cracks.

Evans et al. [10, 11] and Pollock et al. [12] proposed oxideassisted SPLCF crack growth mechanism, in which compressive growth strain in the TGO layer provides the driving force for the penetration of cracks into the substrate during compressive hold. TEM observation at a tip of a short crack (about $30 \mu \mathrm{m}$ deep) revealed high density of slip lines ahead of the crack tip (Figure 6(a)). The slip lines exhibited a converging configuration, similar to the dislocation substructure observed beneath nanoindents [13], which indicates intrusion of the TGO layer during the compressive hold, rather than crack opening and growth under the tensile loading. On the other hand, the slip lines ahead of a deeper crack (about $160 \mu \mathrm{m}$ ) exhibited a diverging configuration (Figure 6(b)), which indicates crack growth under the tensile loading. Therefore, there is a transition in SPLCF crack growth mechanism at crack depth of about 50 to $75 \mu \mathrm{m}$.

Crack growth statistics were recorded by analyzing optical and SEM micrographs. Figure 7 shows the depth of the deepest crack found by X-ray microtomography in each interrupted specimen, plotted against fraction of the expected life. It can be noticed that the depth of the deepest crack starts to increase quickly after about $60 \%$ of the expected life. SEM fractographs of Figure 8 showed similar general features as in [1-3] for René N5 and CMSX4. Single or multiple surface crack initiation sites were found, and some of them were associated with casting pores close to the surface. Cracks propagated perpendicular to loading direction at early stage and deviated to $\{111\}$ crystallographic planes at a later stage.

Overall experimental data suggests that incipient SPLCF cracks grow sequentially through three phases: microstructurally small cracks, mechanically short cracks and large cracks (see Figure 9). The segmentation cracks are essentially microstructurally small cracks, and their growth is driven by the intrusion of TGO layer during the compressive hold. The mechanically short cracks are the cracks growing below the fatigue threshold. These cracks are simply small in size and show same growth behavior as that of the large cracks, and their growth is governed by the tensile loading of a SPLCF cycle. The presence of large casting pore at the free surface may cause segmentation crack to skip the oxide assisted growth mechanism and follow the mechanically short crack growth behavior.

\section{Crack Growth Model}

Based on the above observations, the SPLCF crack growth behaviors of microstructurally small cracks and mechanically short and long cracks can be modeled using the oxide-assisted crack growth mechanism and linear elastic fracture mechanics, respectively.

\section{Oxide-Assisted Crack Growth model}

Following the approach proposed by Evans et al. [10, 11], FEM simulations were carried out to estimate the crack growth rate of the segmentation cracks growing by the oxide-assisted growth mechanism. Plane strain (2D) finite element simulations were performed to grow the fatigue crack as per this mechanism. Due to geometric symmetry of the problem, only half of the geometry was simulated. To this end, a square geometry of $3 \mathrm{~mm}$ size with edge-crack at the top left corner was analyzed [see Figure 10(a)]. 


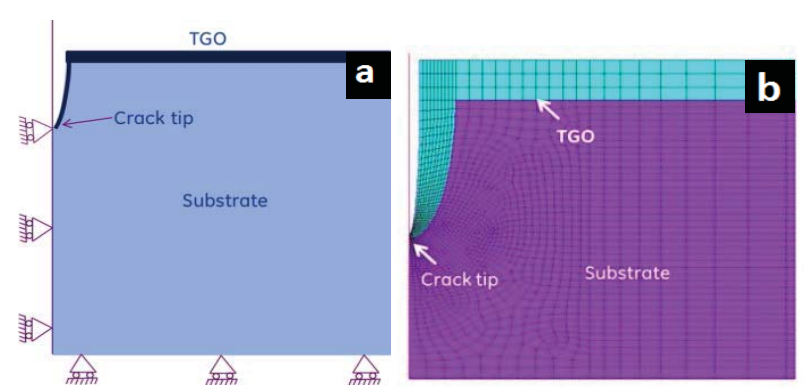

Figure 10. (a) Schematics (not to the scale) of edge-crack geometry analyzed in FE simulation with the boundary conditions. The SPLCF load is applied on right edge of the geometry. (b) Zoomed in view of typical finite element mesh used in the analysis.

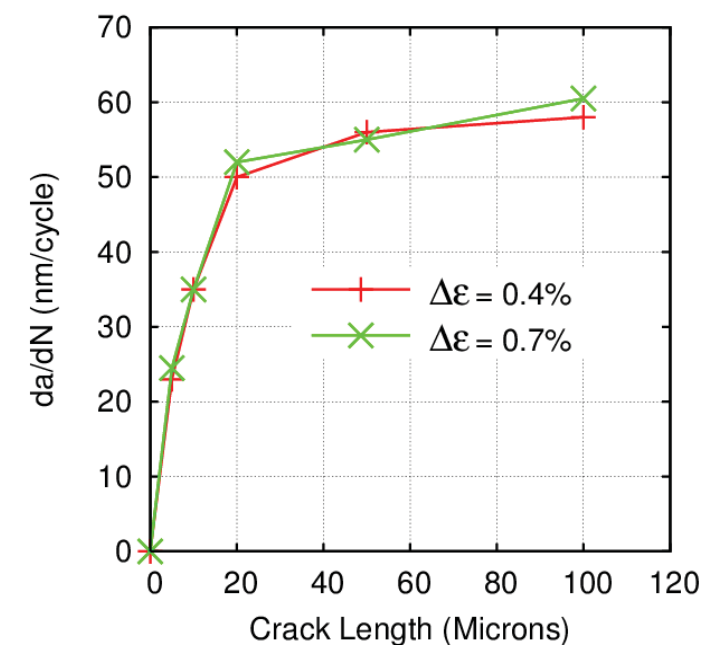

Figure 11. SPLCF crack growth rate $(\mathrm{da} / \mathrm{dN})$ predicted by oxide-assisted growth mechanism for compression hold at $1093{ }^{\circ} \mathrm{C}$ and applied total strain ranges of $0.4 \%$ and $0.7 \%$. The TGO growth strain rate was taken $0.3 \%$ per SPLCF cycle.

The crack face and the free surface were covered with the thermally grown oxide (TGO). Motivated by the SEM micrographs of the SPLCF crack tip regions, the TGO thickness in the FE simulation was taken as $1.5 \mu \mathrm{m}$ at the free surface and it was gradually decreased up to $300-800 \mathrm{~nm}$ at the crack tip (see Figure 5), depending upon the crack depth. TGO thickness at the crack tip was taken as $800 \mathrm{~nm}$ for the $5 \mu \mathrm{m}$ deep crack and 300 $\mathrm{nm}$ for the $100 \mu \mathrm{m}$ deep crack. The crack depths of 5, 10, 20, 50 and $100 \mu \mathrm{m}$ were analyzed in the FE simulation.

The crack geometry was discretized with 4-node quadrilateral elements as shown in the Figure 10(b). The contact algorithm was used to simulate the contact between the two crack faces. The symmetry boundary conditions were applied on the bottom and left edge of the geometry (see Figure 10(a)). The displacement based boundary conditions were applied on the right edge of the geometry to impose cyclic SPLCF loading. In a typical SPLCF load cycle, the peak strain of $0.4 \%$ and $0.7 \%$ were applied. The loading conditions (loading-hold-unloading times) applied in the simulations were same as those used in the SPLCF experiments. The simulations were performed for the compression hold $(\mathrm{A}=-1)$. In all the simulations crack growth rate response was computed for 50 SPLCF load cycles.

The Norton creep law $\left(\dot{\varepsilon}=A \sigma^{n}\right)$ was used to model the high temperature creep response of both, the TGO and the René N5 substrate. No plasticity response was considered in the analysis. The isotropic growth strain rate of $0.3 \%$ per SPLCF cycle was prescribed for TGO elements [14]. This growth strain rate was uniformly applied over a cycle period.

All the simulations were performed with the commercial finite element software ANSYS. The TGO growth strain rate was prescribed by writing a user swell subroutine. To alleviate the problem of extensive mesh distortion in the crack tip region, rezoning/remeshing technique was employed after every 10 SPLCF load cycles.

Figure 11 summarizes the crack growth rate $(\mathrm{da} / \mathrm{dN})$ at different crack depths when SPLCF crack grows by the oxide assisted growth mechanism. FE simulation suggests that, at smaller crack depths, the crack growth rate increases as crack grows deeper. However, the crack growth rate saturates at about 50-60 nm/cycle at $1093{ }^{\circ} \mathrm{C}$ when the TGO growth strain rate is taken as $0.3 \%$ per cycle. The simulations also suggested that the crack growth rate was least sensitive to the applied strain range.

\section{Crack Growth under Tensile Stress}

Paris law was use to characterize the crack growth rates of both mechanically short and long cracks as suggested in $[15,16]$. The empirical expression provided by Raju \& Newman [17] was used to calculate the stress intensity factor $(\mathrm{K})$ for a semi-elliptical surface crack. The model parameters of Paris law pertaining to a long crack were obtained from crack growth rate measurements from ASTM fatigue test specimen tested at $1093{ }^{\circ} \mathrm{C}$ and $982{ }^{\circ} \mathrm{C}$. Whereas, the corresponding parameters for the short crack growth were obtained from the deepest crack measurements taken from the interrupted SPLCF test specimens.

The initial flaw size used in the Paris law pertaining to the short crack was taken as the porosity size observed in the fracture surfaces. The transition from the short crack growth model to the large crack growth model was assumed to happen at the crack depth when the crack growth rates from both models were equal. Alternately, the crack depth at which alternating stress intensity factor $(\Delta \mathrm{K})$ is equal to the fatigue threshold can also be used as a criterion for model transition from short to long crack growth.

Figure 7 also shows the model predictions of crack depth at different fractions of the expected life. The initial flaw size $\left(a_{0}\right)$ and crack depth $\left(\mathrm{a}_{\mathrm{T}}\right)$ at which the model transition occurs are also highlighted in the Figure. It can be noticed from Fig. 7 that the LEFM based model can indeed capture the growth of the short and long SPLCF cracks and also predict the failure life with reasonable accuracy.

Figure 12 shows predicted crack growth rate as a function of crack depth at $1093{ }^{\circ} \mathrm{C}, 0.4 \%$ total strain range and at $982^{\circ} \mathrm{C}$, $0.7 \%$ total strain range for all the mechanisms. Both the FEM simulation of oxide assisted crack growth and the LEFM based 

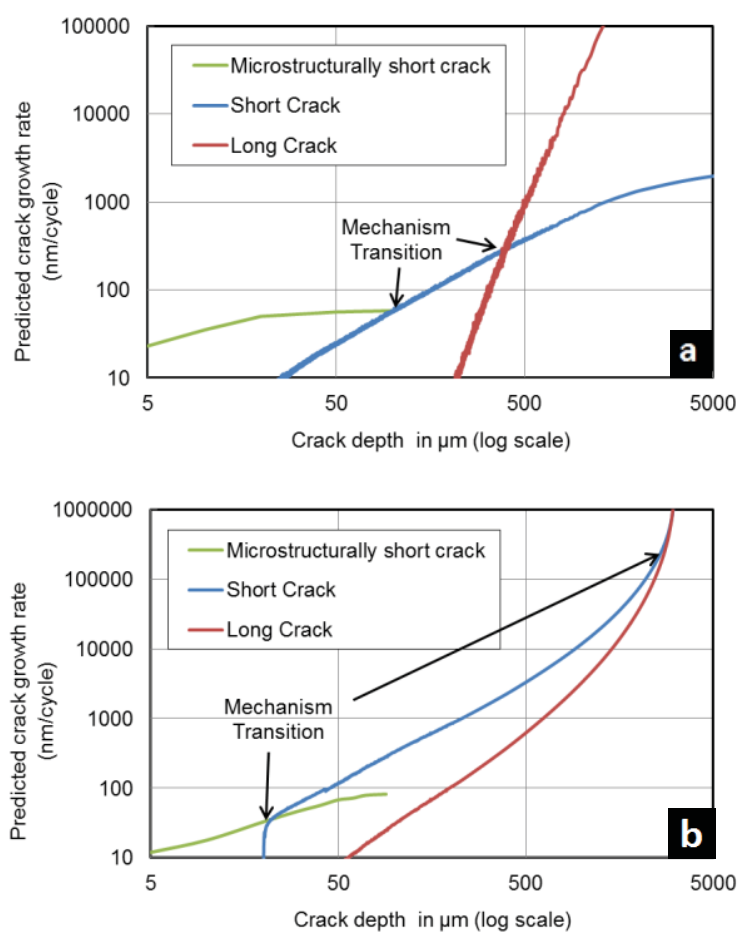

Figure 12. Predicted crack growth rates and transitions of crack growth mechanisms as a function of crack depth at (a) $1093{ }^{\circ} \mathrm{C}$ and $0.4 \%$ total strain range and (b) $982{ }^{\circ} \mathrm{C}$ and $0.9 \%$ total strain range

model for short crack estimate similar crack growth rate of about 45 to $50 \mathrm{~nm} /$ cycle when crack is about $75 \mu \mathrm{m}$ deep at $1093{ }^{\circ} \mathrm{C}$ and $0.4 \%$ total strain range (Figure $12(\mathrm{a})$ ). This corroborates well with the experimental observations that showed converging slip lines at $30 \mu \mathrm{m}$ deep crack and diverging slip lines at $160 \mu \mathrm{m}$ deep crack (Figure 6). Towards the second mechanism transition, from short to long crack growth (at $400 \mu \mathrm{m}$ deep crack), the growth rate is about $300 \mathrm{~nm} /$ cycle at $1093{ }^{\circ} \mathrm{C}$ and $0.4 \%$ total strain range (Figure 12(a)).

However, Figure 12 (b) suggests that at $982{ }^{\circ} \mathrm{C}$ and $0.9 \%$ total strain range, first mechanism transition happens when crack is about $25 \mu \mathrm{m}$ deep. In this scenario, the presence of large casting pore at the free surface may cause segmentation crack to skip the oxide assisted growth mechanism and follow the mechanically short crack growth behavior. The second mechanism transition, from short to long crack growth is predicted when crack is about $2.5 \mathrm{~mm}$ deep.

\section{Summary}

Damage evolution during compressive hold sustained peak low cycle fatigue (SPLCF) of a Ni-based single-crystal superalloy René N5 was investigated using both experiments and modeling. Tensile stress was found to be a critical factor for SPLCF life. Bulk deformation away from cracks showed a signature of dominant creep deformation, including $\gamma^{\prime}$ rafting and formation of interfacial dislocation networks. As temperature, strain range and number of cycles increase, bulk deformation yields increased bulk damage as represented by inclined rafts, higher dislocation activities in both $\gamma$ matrix and $\gamma^{\prime}$ phase. Although bulk damage does not lead to SPLCF failure, compressive creep deformation during hold leads to evolution of tensile stress

The crack growth mechanisms operating at different stages of SPLCF life were identified. When the cracks are microstructurally small, crack growth occurs primarily during the compressive loading, and the growth rate is accelerated by the compressive growth strains of the TGO layer. Once the crack depth reaches mechanically small scale, tensile loading governs the crack growth. The growth rate can be predicted by LEFM. Incorporating these mechanisms as a function of crack depth, SPLCF life was modeled through FEM and LEFM based approach to demonstrate its applicability.

\section{Acknowledgements}

The authors acknowledge assistance of A. Singhal in obtaining Xray microtomography reconstructions of SPCLF tested specimens. The authors also acknowledge support from $\mathrm{S}$. Duclos and $\mathrm{M}$. Blohm.

\section{References}

1. S. Yandt, X.J. Wu, N. Tsuno, and A. Sato, "Cyclic Dwell Fatigue Behavior of Single Crystal Ni-base Superalloys with/without Rhenium," Superalloys 2012, eds. E.S. Huron et al. (Warrendale, PA: TMS, 2012), 501-508.

2. M. Okazaki, K. Take, K. Kakehi, Y. Yamazaki, M. Sakane, M. Arai, S. Sakurai, H. Kaneko, Y. Harada, A. Itoh, T. Okuda, I. Nonaka, K. Fujiyama, and K. Nanba, "Collaborative Research on Thermo-Mechanical and Isothermal Low-Cycle Fatigue Strength of Ni-base Superalloys and Protective Coatings at Elevated Temperatures in the Society of Materials Science, Japan (JSMS)," Thermomechanical Fatigue Behavior of Materials, vol. 4, ASTM STP 1428, ASTM international (2002), 180-194.

3. A. Koster, A.M. Alam, and L. Rémy, “A Physical-Base Model for Life Prediction of Single Crystal Turbine Blades under CreepFatigue Loading and Thermal Transient Conditions," Temperature-Fatigue Interaction, eds. L.Rémy et al. (Kidlington, Oxford, UK: Elsevier Science, 2002), 203-212.

4. S. Muller, J. Rosler, C. Sommer, and W. Hartnagel, "The Influence of Load Ratio, Temperature, Orientation, and Hold Time on Fatigue Crack Growth of CMSX-4," Superalloys 2000, eds. T.M. Pollock et al. (Warrendale, PA: TMS, 2000), 347-356.

5. T. Hino, Y. Yoshioka, Y. Koizumi, T. Kobayashi, and H. Harada, "Development and Evaluation of High Strength Ni-base Single Crystal Superalloy, TMS-82+," Proc. of the International Gas Turbine Congress 2003 Tokyo, ed. T. Watanabe, (Tokyo, Japan: GTSJ, 2003).

6. A. Suzuki, M.F.X. Gigliotti, B.T. Hazel, D.G. Konitzer, and T.M. Pollock, "Crack Progression during Sustained-Peak LowCycle Fatigue in Single-Crystal Ni-Base Superalloy Réne N5," Metallurgical and Materials Transactions A, 41A (2010), $947-$ 956. 
7. C.A. Yablinsky, K.M. Flores, M.J. Mills, J.C. Williams, and J. Rigney, "Fatigue Behavior in Monocrystalline Ni-Based Superalloys for Blade Applications," Superalloys 2008, eds. R,C, Reed et al. (Warrendale, PA: TMS, 2008), 535-540.

8. W.J. Ostergren, "A Damage Function and Associated Failure Equations for Predicting Hold Time and Frequency Effects in Elevated Temperature, Low Cycle Fatigue," Journal of Testing and Evaluation, 4 (1976), 327-340.

9. A. Epishin, T. Link, U. Bruckner, and P.D. Portella, "Kinetics of the Topological Inversion of the $\gamma / \gamma^{\prime}$-Microstructure During Creep of a Nickel-Based Superalloy," Acta Materialia, 49 (2001), 4017-4023.

10. A.G. Evans, M.Y. He, A. Suzuki, M. Gigliotti, B. Hazel, and T.M. Pollock, "A Mechanism Governing Oxidation-Assisted Low-cycle Fatigue of Superalloys," Acta Materialia, 57 (2009) 2969-2983.

11. M.Y. He, and A.G. Evans, "A Model for Oxidation-Assisted Low Cycle Fatigue of Superalloys," Acta Materialia, 58 (2010), 583-591.

12. T.M. Pollock, B. Laux, C.L. Brundidge, A. Suzuki, and M.Y. $\mathrm{He}$, "Oxide-Assisted Degradation of Ni-Base Single Crystals
During Cyclic Loading: the Role of Coatings," J. Am. Ceram, Soc., 94 (2011), S136-S145.

13. S. J. Lloyd, A. Castellero, F. Giuliani, Y. long, K. K. McLaughlin, J. M. Molina-Aldareguia, N. A. Stelmashenko, L. J. Vandeperre and W. J. Clegg, "Observations of Nanoindents via Cross-sectional Transmission Electron Microscopy: a Survey of Deformation Mechanisms," Proc. R. Soc. A, 461 (2005), 25212543.

14. A. Suzuki, Y. Gao, D. Lipkin, A. Singhal, M. Krug, D. Konitzer, J. Almer, T. Pollock, and B. Bewlay, "Oxide-assisted Crack Growth in Hold-time Low-cycle-fatigue of Single-crystal Superalloys," MATEC Web of Conferences, 14 (2014), 04004.

15. F. Schubert, T. Rieck and P.J. Ennis, "The Growth of Small Cracks in the Single Crystal Superalloy CMSX-4 at 750 and $1000^{\circ}$ C," Superalloys 2000, eds. T.M. Pollock et al. (Warrendale, PA: TMS, 2000), 341-346.

16. L. Grabowski and J.E. King, "Modelling Short Crack Growth Behavior in Nickel-base Superalloys," Fatigue Fracr. Engng Mater. Struct., 15 (1992), 595-606.

17. I.S. Raju and J.C. Newman jr., "Stress-intensity Factors for a Wide Range of Semi-elliptical Surface Cracks in Finite-thickness Plates," Engg. Frac. Mech., 11 (1979), 817-829. 